\title{
SISTEM KENDALI ROTASI MATAHARI PADA PANEL SURYA BERBASIS ARDUINO UNO
}

\author{
Muhtar Nurdiansyah ${ }^{*}$,1), Erick Chomper Sinurat ${ }^{2)}$, Muhammad Bakri', Imam Ahmad ${ }^{4)}$, Aldi \\ Bagus Prasetyo ${ }^{5}$
}

\author{
${ }^{1,2,3)}$ Program Studi Teknik Komputer, Fakultas Teknik dan Ilmu Komputer, Universitas Teknokrat Indonesia \\ Jl. ZA. Pagar Alam No.9 -11, Labuhan Ratu, Bandar Lampung, Indonesia 35132 \\ 4) Program Studi Sistem Informasi, Fakultas Teknik dan Ilmu Komputer, Universitas Teknokrat Indonesia \\ Jl. ZA. Pagar Alam No.9 -11, Labuhan Ratu, Bandar Lampung, Indonesia 35132 \\ ${ }^{5)}$ Program Studi Teknologi Informasi, Fakultas Teknik dan Ilmu Komputer, Universitas Teknokrat Indonesia \\ Jl. ZA. Pagar Alam No.9 -11, Labuhan Ratu, Bandar Lampung, Indonesia 35132 \\ Email: ${ }^{1}$ nurdiansyah.muhtar@gmail.com
}

\begin{abstract}
Permanently installed solar panels will not get tracking maximum power point. In order to be able to produce a power point maximum, solar panels need to be controlled in the direction of the sun's movement. In this work, a system design that is able to control is described a solar panel with 2 freedom tracks based on the Arduino Uno microcontroller, namely the movement of east to west according to the rotation of the earth and movement towards the north to the south according to the earth's revolution to get tracking of power points maximum. The results showed that the prototype system was designed, capable of controlling the steering of a servo motor on a solar panel, either automatically with 2 circulation paths to get tracking of power points maximum.
\end{abstract}

Keywords: Arduino UNO, control system, LCD I2C, motor servo, solar panel

\section{Abstrak}

Panel surya yang dipasang secara permanen tidak akan mendapatkan penjejakan titik daya maksimum. Agar dapat menghasilkan titik daya secara maksimum, panel surya perlu dikendalikan mengikuti arah pergerakkan matahari. Pada penelitian ini dideskripsikan rancangan sistem yang mampu mengendalikan panel surya dengan 2 lintasan kebebasan berbasis mikrokontroler Arduino Uno, yaitu pergerakan arah timur ke barat sesuai rotasi bumi dan pergerakan arah utara ke selatan sesuai revolusi bumi untuk mendapatkan penjejakan titik daya maksimum. Hasil penelitian menunjukkan bahwa purwarupa sistem yang dirancang, mampu mengendalikan kemudi motor servo pada panel surya, baik secara otomatis dengan 2 lintasan edar untuk mendapatkan penjejakan titik daya maksimum.

Kata Kunci: Arduino UNO, LCD I2C, motor servo, panel surya, sistem kontrol

\section{Pendahuluan}

Indonesia adalah negara tropis yang dilewati oleh garis katulistiwa memiliki intensitas matahari yang tinggi pertahunnya. Panel surya merupakan alat yang digunakan untuk mendapatkan energi alternatif yang bersumber dari cahaya matahari. Energi yang dihasilkan dari panel surya dipengaruhi oleh beberapa faktor, salah satunya adalah faktor sinar datangnya matahari atau sinar UV (Ultra Violet). Sinar matahari pada tiap jamnya berubah-ubah yang diakibatkan karena adanya rotasi bumi yang berputar pada sumbunya atau biasa disebut rotasi bumi. Pada umumnya panel surya yang terpasang pada instalasi tidak mengalami perubahan posisi mengikuti sinar UV pada matahari dan tidak ada pengolahan arus yang dihasilkan dari sinar matahari ketika penyimpanan sudah penuh. Hal itu mengakibatkan tidak optimalnya tegangan yang dihasilkan panel surya.

Matahari merupakan sumber energi yang bergerak dan setiap derajat matahari bergerak akan mempengaruhi besar penerimaan intensitas cahaya yang akan diterima oleh suatu alat / bahan yang disebut panel surya. Panel surya akan menghasilkan energi listrik sesuai besar intensitas cahaya yang diterimanya dari pancaran cahaya matahari. Untuk memanfaatkan energi cahaya matahari dengan maksimal maka panel surya ini harus terus diarahkan sesuai dengan arah pancaran cahaya matahari. Arus listrik merupakan besaran penting untuk mengetahui produktivitas panel surya menghasilkan daya listrik. Selain itu arus juga sangat penting untuk diamati karena panel surya hanya bekerja pada siang hari atau saat 2 ada cahaya. Semakin besar intensitas cahaya matahari yang ditangkap oleh panel surya, semakin besar daya listrik yang dihasilkan. Oleh karena itu penelitian ini bertujuan membuat sistem kendali rotasi matahari pada panel surya yang menggunakan sensor yang semua sistemnya dikontrol oleh mikrokontroler Arduino UNO [1], yang dapat mempermudah pekerjaan manusia dengan memanfaatkan kemajuan teknologi [2][3][4].

Cara kerjanya menggunakan sensor cahaya LDR (Light Dependent Resistor) yang berfungsi untuk mengikuti arah sinar UV dari matahari. Dari sensor cahaya yang digunakan untuk mengikuti atau mengatur 
perubahan sudut kemiringan panel surya dengan menggunakan motor servo sebagai penggerak [5][6]. Hal ini agar pada setiap perubahan waktu, panel surya dapat meningkatkan penangkapan pancaran sinar matahari. Jika pancaran sinar matahari yang diterima panel sel surya dapat ditingkatkan, maka tegangan yang dihasilkan panel suryapun dapat meningkat dibandingkan dengan panel surya tanpa menggunakan sistem ini.

\section{Metode}

\section{A. Sistem Kendali}

Sistem kendali adalah kumpulan dari beberapa komponen yang terhubung satu sama lainnya, sehingga membentuk suatu tujuan tertentu yaitu mengendalikan atau mengatur suatu sistem [1]. Sistem kendali dapat dibagi menjadi dua jenis yaitu sistem kontrol loop terbuka dan sistem kontrol loop tertutup. Pada penelitian ini, sistem kendali digunakan untuk melakukan pengontrolan terhadap panel surya berdasarkan rotasi matahari, sehingga akan memperoleh hasil maksimal dalam penyerapan energi nya.

B. Panel Surya

Panel surya merupakan alat yang dapat mengkonversi sinar matahari langsung menjadi energi listrik. Saat ini panel surya sudah banyak digunakan dalam kehidupan sehari-hari. Panel surya yang rata-rata banyak digunakan bersifat tetap. Hal ini membuat penyerapan sinar matahari oleh panel surya kurang optimal. Agar penyerapan sinar matahari oleh panel surya optimal, maka panel surya harus selalu mengikuti pergerakan arah matahari.

Pada penelitian ini diusulkan prototype sistem pelacakan sinar matahari pada sistem pembangkit tenaga surya berbasis Arduino UNO untuk memperoleh energi matahari yangmaksimal. Sistem ini akan membuat panel surya bergerak mengikuti gerak matahari, sehingga penyerapan sinar matahari dapat maksimal.

C. Alat

Penelitian ini dilakukan menggunakan perangkat keras dan perangkat lunak sebagai berikut:

1. Panel surya, berfungsi sebagai alat penyerap sinar dari matahari menjadi energi listrik.

2. Mikrokontroler, berfungsi sebagai pengontrol yang mengatur semua kinerja alat [7][8].

3. Motor servo, berfungsi sebagai penggerak [9] arah panel surya mengikuti sinar UVatau matahari dengan 2 aksis dari barat ke timur.

4. LDR, berfungsi sebagai sensor pendeteksi cahaya untuk mengikuti arah matahari.

5. Baterai, sebagai penyimpan energi yang dihasilkan oleh panel surya.

6. LCD I2C, berfungsi sebagai penampil tegangan volt dan ampere [10] panel surya dan baterai.

7. USB Charger, berfungsi sebagai charger ke baterai.

8. USB Boster, berfungsi sebagai output arus listrik DC

9. DC Power, berfungsi sebagai catu daya atau sebagai power arus untuk Arduino [11].
D. Tahapan Penelitian

Penelitian yang dilakukan mencakup beberapa tahapan yaitu, perancangan diagram blok, perancangan rangkaian catu daya, perancangan rangkaian keseluruhan alat, dan penggunaan software Arduino IDE. Berikut penjelasan dari setiap tahapan yang dilakukan:

1. Perancangan diagram blok, skema diagram dari sistem kendali rotasi panel surya dapat dilihat pada Gambar 1.

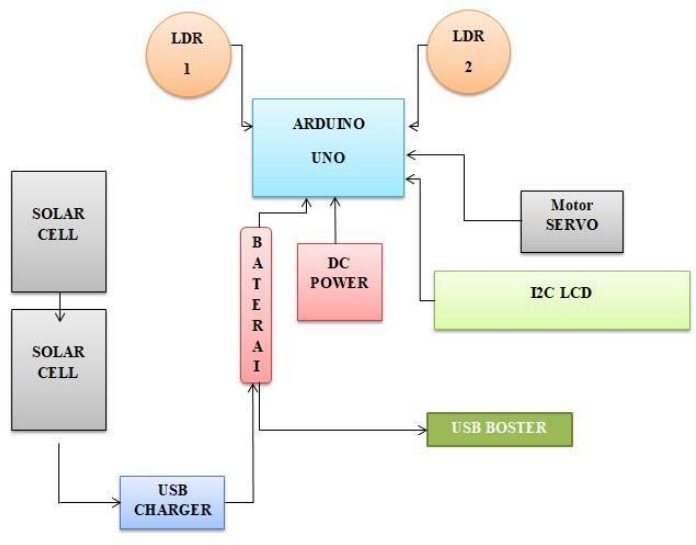

Gambar 1. Skema diagram blok

Berdasarkan Gambar 1 diatas, dapat diuraikan skema kerjanya sebagai berikut:

Alat panel surya ini dapat memaksimalkan penangkapan sumber energi listrik yang dihasilkan dari sinar UV dengan menggunakan sistem tracking rotasi matahari agar benar-benar dapat memanfaatkan sinar UV pada saat matahari menjelang terbit dan terbenam. Dari hasil pengujian yang telah didapatkan bahwa tingkat jumlah tegangan tertinggi berada pada jam 11.30 sampai 12.30. hal ini disebabkan karena matahari tepat berada di atas lintas edar matahari harian. Alat ini juga dapat memanfaatkan energi pada saat daya yang sudah tertampung penuh dalam baterai dapat langsung digunakan untuk menghidupkan alat elektronik, sehingga dapat meningkatkan penggunaan energi listrik yang dihasilkan.

Cara kerja pada alat ini yaitu ketika alat telah diletakkan di area terbuka maka alat akan membaca sumber cahaya terbesar dengan menggunakan 2 buah sensor LDR dan 1 buah motor servo DC sebagai penggerak alat untuk mengarahkan panel surya sesuai rotasi matahari, untuk penangkapan sinar UV dapat tertangkap secara maksimal. Setelah memulai penangkapan sinar UV, arus listrik yang didapatkan disimpan kedalam baterai chager dengan tegangan 3.7 volt dan output dari baterai 3 volt. Alat ini juga menggunakan 2 buah panel surya yang di paralel agar pengisisan baterai dapat lebih cepat. Status pengisian baterai juga dapat ditampilkan di LCD I2C mulai dari tegangan ampere dan volt.

2. Perancangan rangkaian catu daya, dibutuhkan untuk mensuplai daya pada rangkaian. Karena hanya mikrokontroler yang memerlukan sumber tegangan langsung dari USB laptop, sedangkan komponen lain mengambil tegangan dari mikrokontroler. 
3. Perancangan rangkaian keseluruhan alat, terdiri dari beberapa komponen yang saling terintegrasi. Rangkaian keseluruhan alat dapat dilihat pada Gambar 2.

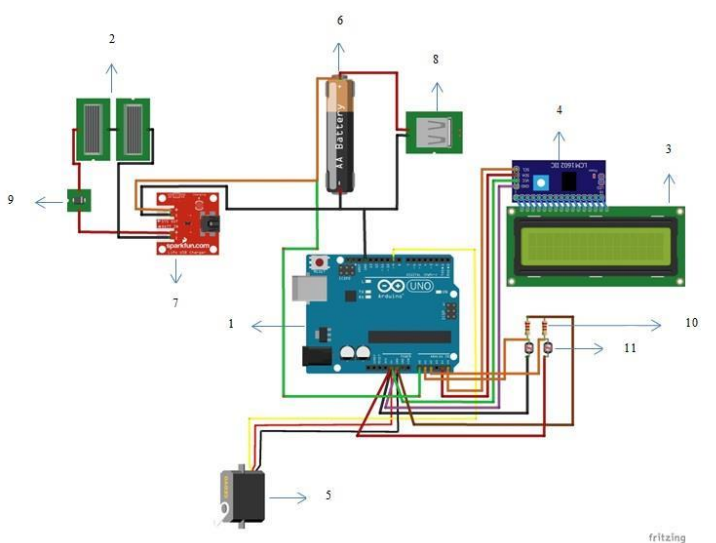

Gambar 2. Rangkaian keseluruhan alat

Pada Gambar 2 ditunjukkan rangkaian elektronika keseluruhan alat yang dibuat/terdapat beberapa komponen utama yang penting untuk membuat alat dapat beroperasi dimana Arduino UNO pada port 5V, GND dan $\sim 9$ terhubung dengan motor servo, port $5 \mathrm{~V}, \mathrm{~A} 1$ dan $\mathrm{A} 2$ terhubung dengan 2 sensor LDR, lalu pada panel surya terhubung pada port BATT IN Plus dan Minus Lipo USB Charging, baterai terhubung dengan port GND dan A0, LCD I2C terhubung dengan port GND, 5V, A4 dan A5. LCD I2C yang berfungsi mengetahui kondisi tegangan pada arus masuk baterai dan presentase jumlah isi daya baterai dalam satuan persen. Rangkaian keseluruhan alat kemudian akan dibuatkan rangkaian mekanika guna penggabungannya berupa mockup alat. Mockup alat merupakan desain realisasi alat sebelum alat dilakukan pengimplementasian alat, berikut desain mekanika alat yang ditunjukkan pada Gambar 3.

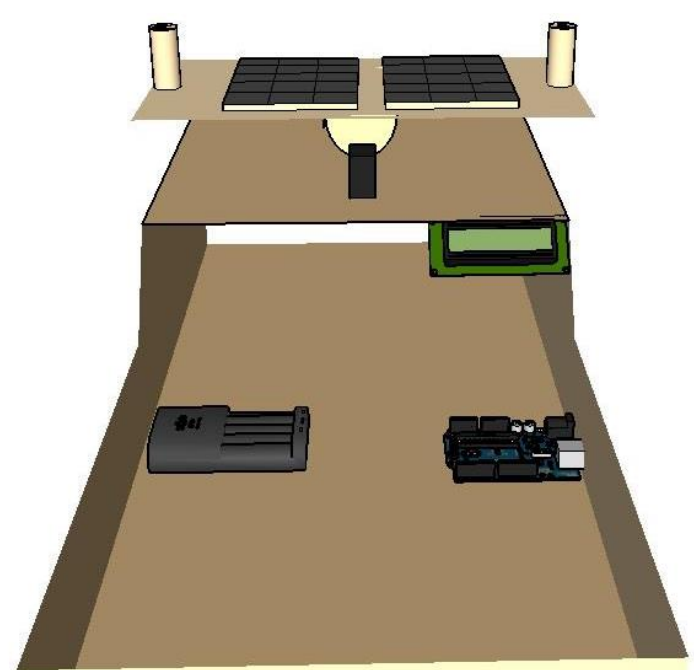

Gambar 3. Desain mockup alat
4. Penggunaan software Arduino IDE, merupakan tahapan yang penting sebab dari sinilah program dibuat dan diunggah menggunakan software Arduino, hal ini bertujuan untuk menyisipkan kode program kedalam Arduino. Pada tahap ini juga dilakukan penulisan kode program untuk memberikan intruksiintruksi menggunakan bahasa pemrograman $\mathrm{C}++$ yang bertujuan untuk menjalankan sistem agar dapat bekerja sesuai kode program yang telah diisikan kedalam sebuah Arduino UNO. Berikut adalah tampilan layer untuk mengisikan kode program pada software Arduino IDE ditunjukkan pada Gambar 4.

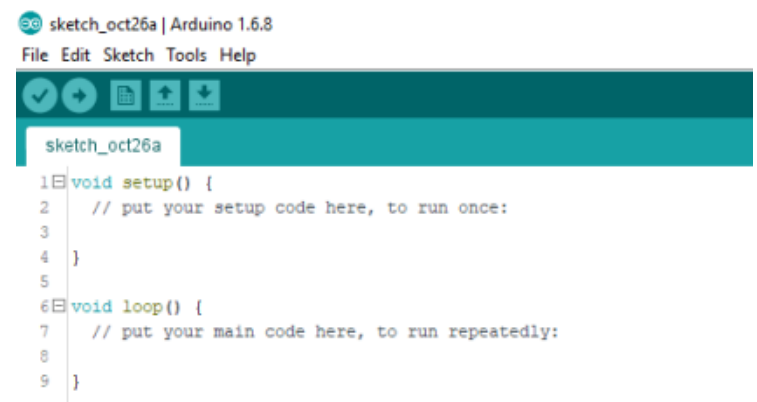

Gambar 4. Layer penulisan program

\section{Hasil dan Pembahasan}

Pada penelitian ini, alat berhasil dibangun menggunakan beberapa komponen, yakni sensor LDR, panel surya, Arduino UNO, motor servo DC, LCD i2c, USB charger, USB booster, dan battery $3.7 \mathrm{v} 4800 \mathrm{mAh}$. Sensor terletak dibagian atas panel surya, sensor ini terhubung pada port A1 dan A2 pada Arduino UNO, ini berfungsi sebagai pendeteksi cahaya. Panel Surya yang terpasang pada alat merupakan sebuah media yang berfungsi sebagai pengkonversi sinar matahari yang didapatkan dan diolah menjadi energi listrik dengan tegangan dan daya yang berbeda-beda, sesuai dengan kondisi cahaya dan besar penampungan panel surya. Gambar 5 merupakan tampilan dari panel surya yang akan terkoneksi dengan usb charger agar dapat dilakukan pengkonversian energi listrik, namun sebelum itu dibutuhkan sebuah dioda untuk menyearahkan arus yang masih bersifat AC.

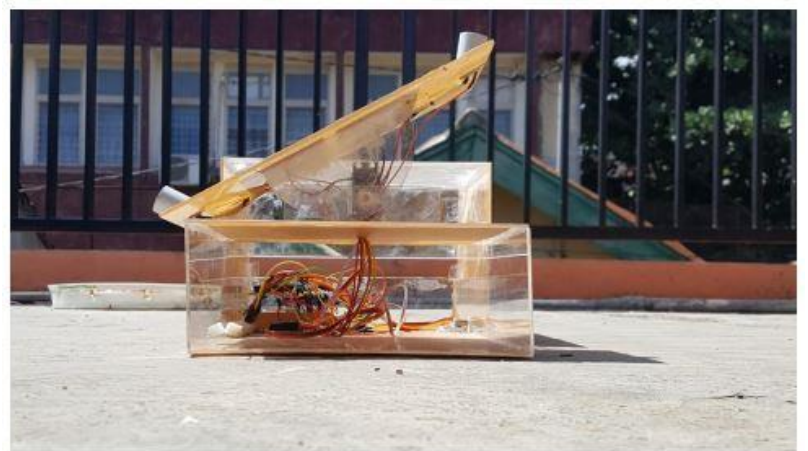

Gambar 5. Sistem kendali rotasi matahari pada panel surya 


\section{A. Alur Proses}

Secara umum, alat yang dibangun memiliki memiliki alur proses seperti ditunjukkan pada Gambar 6 .

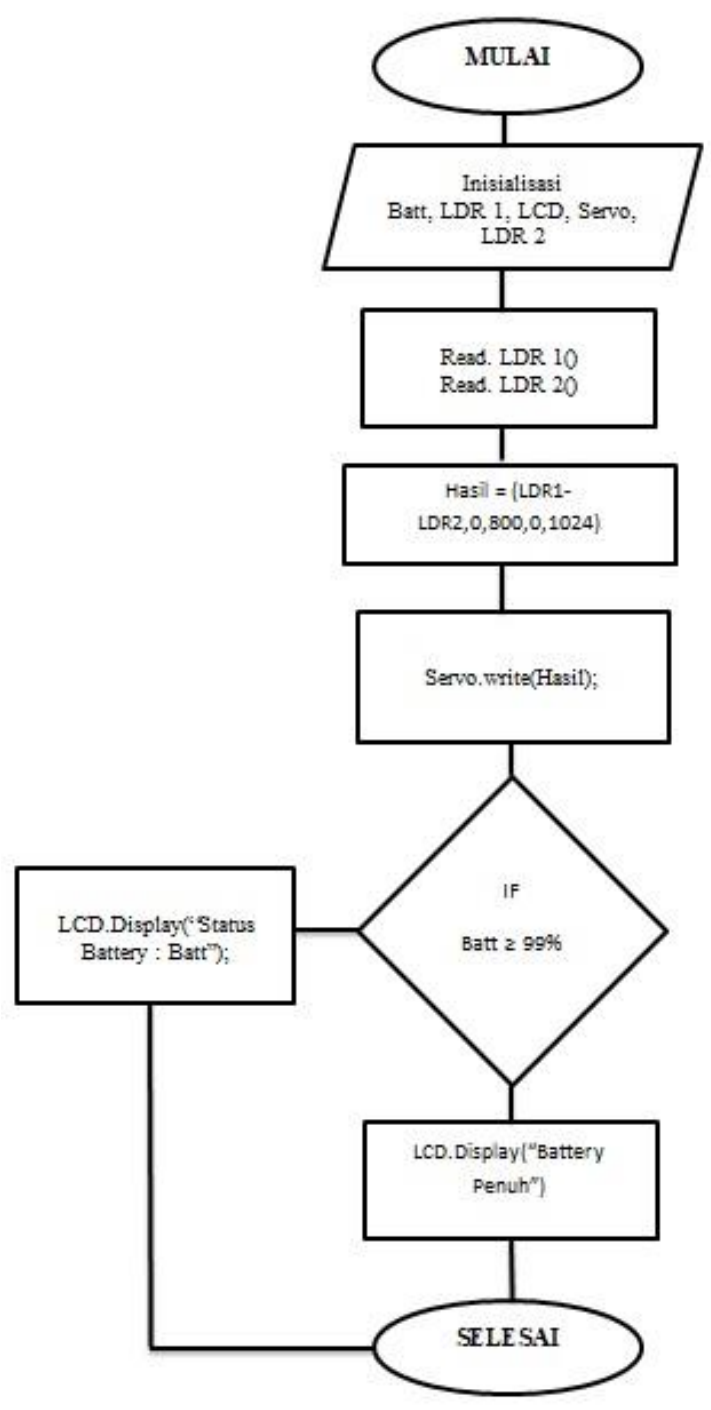

Gambar 6. Flowchart system kerja alat

Pada Gambar 6 diatas menjelaskan tentang bagaimana cara kerja dan proses alat bekerja: Berawal dari mulai saat catu daya dihubungkan dengan mikrokontroler, lalu mulai sebuah inisialisasi awal yaitu panel surya, battery, servo, LDR dan variabel-variabel yang digunakan. Setelah semua terkoneksi ke mikrokontroler maka langkah selanjutnya adalah melakukan pemasangan battery kedalam socket yang telah disediakan, setelah socket berhasil dipasang, langkah selanjutnya adalah meletakan alat ke luar rumah, setelah itu 2 buah sensor LDR akan merespon cahaya matahari yang dia dapat dan mengkalkulasikannya secara matematis sehingga didapatkan nilai rata-rata dari operasi 2 buah sensor LDR tersebut sehingga servo akan bergerak sesuai dengan nilai yang didapatkan berdasarkan nilai LDR yang didapatkan disaat yang sama pula LCD akan menampilkan status dari pada battery alat yang mana terdapat 2 buah status yang pertama adalah voltage dari battery yang kedua adalah status presentase battery yang sedang di-charge.

\section{B. Pengujian}

Pengujian dilakukan dengan meletakkan alat di tempat terbuka seperti di atas rumah supaya dapat mendapatkan sinar matahari dan tidak terhalang benda apapun. Hasil pengujian servo alat yang akan dibaca dengan menggunakan fungsi pada arduino yaitu myservo.read(). Fungsi tersebut digunakan untuk membaca nilai dari posisi servo saat ini. Dikarenakan nilai servo yang berubah-ubah karena perubahan intensitas cahaya membuat nilai dari posisi servo saat ini tidak diketahui maka dengan fungsi myservo.read() akan menampilkan nilai dari posisi servo tersebut. Tampilan pengujian dari alat dapat dlihat pada Gambar 7 sampai Gambar 12

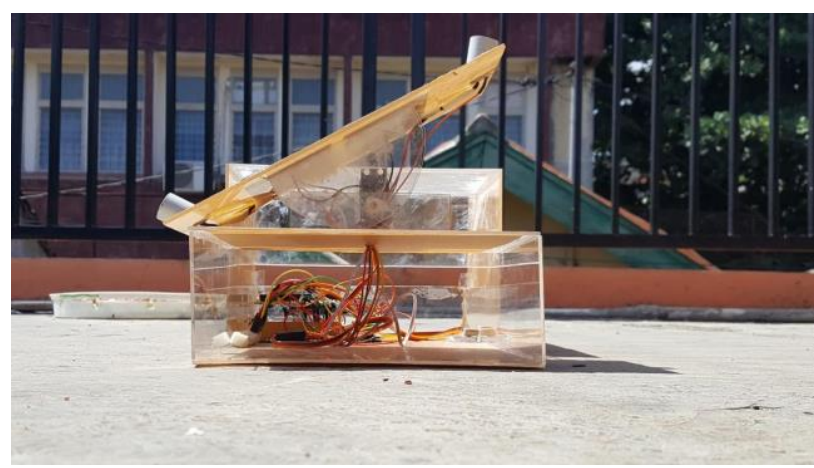

Gambar 7. Posisi servo $83^{\circ}$ (pukul 11:00)

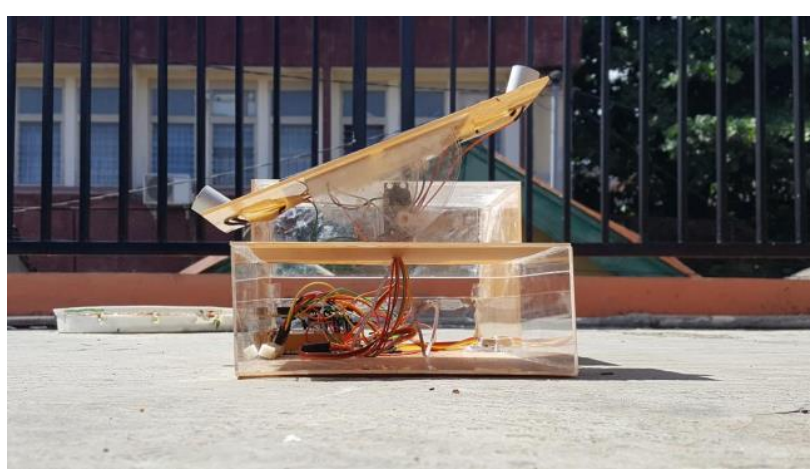

Gambar 8. Posisi servo $86^{\circ}$ (pukul 11.30)

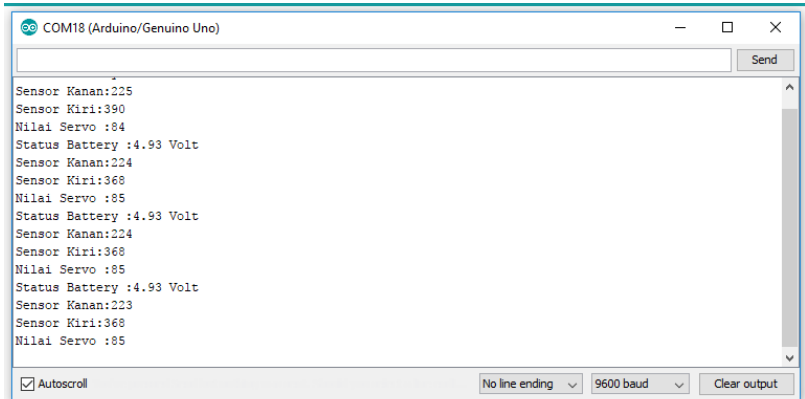

Gambar 9. Hasil pembacaan nilai servo 1

Dari tampilan serial monitor pada Gambar 9 dapat dilihat nilai sensor kanan yang pertama adalah 225 dan sensor kiri yang pertama 390 dari perbandingan skala nilai 
tersebut didapatkan posisi servo yaitu 84, yang terakhir kanan 223 dan yang terakhir kiri 368 menghasilkan posisi servo 85 .

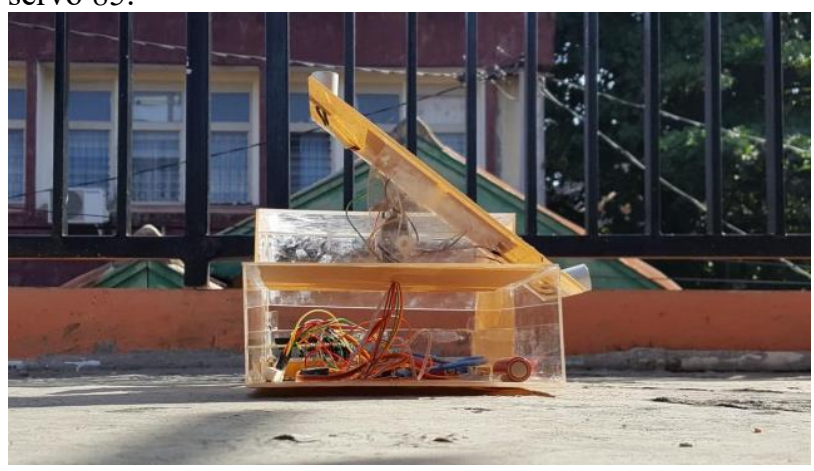

Gambar 10. Posisi servo $92^{\circ}$ (pukul 11:45)

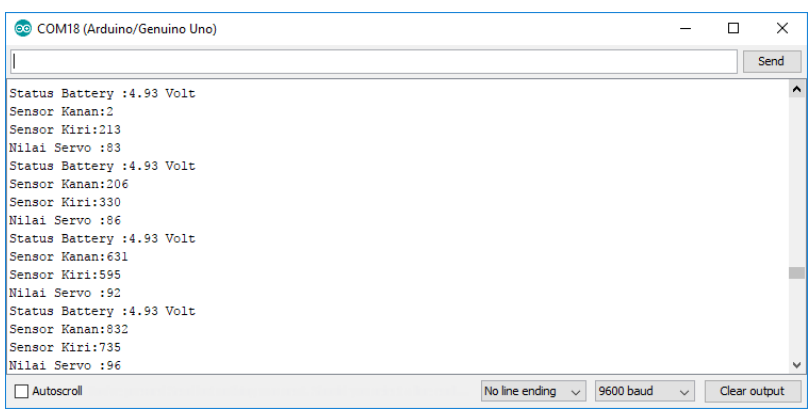

Gambar 11. Hasil pembacaan nilai servo 2

Dari tampilan serial monitor pada Gambar 11 dapat dilihat nilai sensor kanan yang pertama adalah 2 dan sensor kiri yang pertama 213 dari perbandingan skala nilai tersebut didapatkan posisi servo yaitu 83 , yang terakhir kanan 832 dan yang terakhir kiri 735 menghasilkan posisi servo 96.

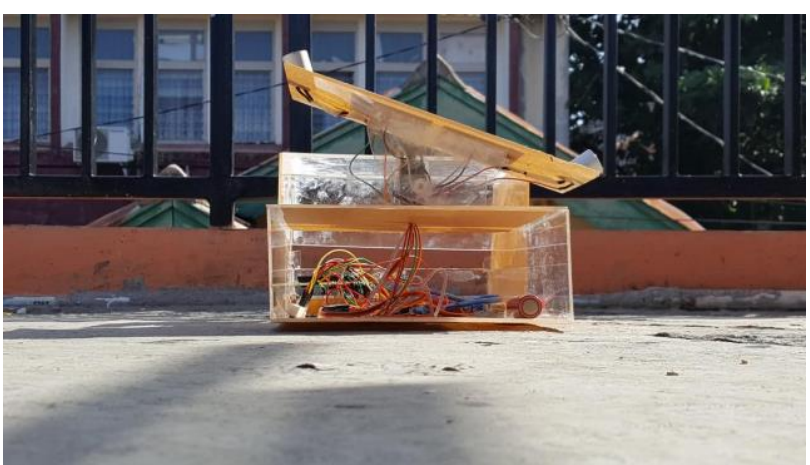

Gambar 12. Posisi servo $96^{\circ}$ (pukul 12:00)

Berdasarkan pengujian yang telah dilakukan, rangkuman hasil yang diperoleh ditunjukkan pada Tabel 1 .
Tabel 1. Pengujian servo 1 dan 2

\begin{tabular}{cccc}
\hline $\begin{array}{c}\text { Waktu } \\
\text { Pengujian } \\
\text { (WIB) }\end{array}$ & $\begin{array}{c}\text { Sensor LDR } \\
\text { Kanan }\end{array}$ & $\begin{array}{c}\text { Sensor LDR } \\
\text { Kiri }\end{array}$ & $\begin{array}{c}\text { Posisi } \\
\text { Servo }\end{array}$ \\
\hline 10.30 & 225 & 390 & $84^{\circ}$ \\
10.35 & 224 & 368 & $85^{\circ}$ \\
10.45 & 223 & 368 & $85^{\circ}$ \\
11.00 & 213 & 2 & $83^{\circ}$ \\
11.30 & 206 & 330 & $86^{\circ}$ \\
11.45 & 631 & 595 & $92^{\circ}$ \\
12.00 & 832 & 735 & $96^{\circ}$ \\
\hline
\end{tabular}

\section{Kesimpulan dan Saran}

Berdasarkan hasil penelitian dan pembahasan maka dapat disimpulkan sebagai berikut: 1) Panel Surya dapat berjalan dengan baik, mampu melakukan pengisian daya ke battery saat terdapat sinar matahari; 2) Servo pada alat mampu berjalan dengan baik dikarenakan mampu berubah-ubah posisi sesuai dengan nilai yang didapatkan oleh 2 buah sensor LDR; 3) Kalkulasi hasil penangkapan sinar UV dalam solar panel yang optimal diperoleh pada pukul 10.30 sampai dengan pukul 14.30 pada rotasi matahari.

Berdasarkan perancangan dan hasil implementasi program yang dilakukan maka saran yang perlu diperhatikan dalam pengembangan sistem ini adalah sebagai berikut: 1) Penambahan sensor waterdrop untuk mendeteksi saat ada hujan dan mampu melindungi alat dari air hujan dengan trigger tertentu; 2) LCD dapat menampilkan arus masuk dari solar panel; 3) Diperlukan alat joul tief untuk meningkatkan tegangan dan konversi yang voltasenya lebih besar.

\section{Daftar Pustaka}

[1] T. Susanto, S. D. Riskiono, Rikendry, and A. Nurkholis, "Implementasi Kendali LQR Untuk Pengendalian Sikap Longitudinal Pesawat Flying Wing," J. Electro Luceat, vol. 6, no. 2, pp. 245-254, 2020, doi: https://doi.org/10.32531/jelekn.v6i2.257.

[2] A. Nurkholis, A. Riyantomo dan M. Tafrikan, "Sistem pakar penyakit lambung menggunakan metode forward chaining," Majalah Ilmiah Momentum, vol. 13, no. 1, 2017.

[3] A. Nurkholis and I. S. Sitanggang, "Optimalisasi model prediksi kesesuaian lahan kelapa sawit menggunakan algoritme pohon keputusan spasial," $J$. Teknol. dan Sist. Komput., vol. 8, no. 3, pp. 192-200, 2020, doi: 10.14710/jtsiskom.2020.13657.

[4] A. Nurkholis and I. S. Sitanggang, "A spatial analysis of soybean land suitability using spatial decision tree algorithm," in Sixth International Symposium on 
LAPAN-IPB Satellite, Dec. 2019, no. December, p. 113720I, doi: 10.1117/12.2541555.

[5] A. P. Zanofa, R. Arrahman, M. Bakri, and A. Budiman, "Pintu Gerbang Otomatis Berbasis Mikrokontroler Arduino UNO R3," J. Tek. dan Sist. Komput., vol. 1, no. 1, pp. 22-27, 2020.

[6] A. T. Wahyudi, Y. W. Hutama, M. Bakri, and S. D, Riskiono, "Sistem Otomatis Pemberian Air Minum Pada Ayam Pedaging Menggunakan Mikrokontroller Arduino dan RTC DS1302," J. Tek. dan Sist. Komput., vol. 1, no. 1, pp. 22-28, 2020.

[7] S. Samsugi, Z. Mardiyansyah, and A. Nurkholis, "Sistem Pengontrol Irigasi Otomatis Menggunakan Mikrokontroler Arduino UNO," J. Teknol. dan Sist. Tertanam, vol. 1, no. 1, pp. 17-22, 2020.
[8] Hayatunnufus and D. Alita, "Sistem Cerdas Pemberi Pakan Ikan Secara Otomatis," J. Teknol. dan Sist. Tertanam, vol. 1, no. 1, pp. 11-16, 2020.

[9] I. K. Gunawan, A. Nurkholis, and A. Sucipto, "Sistem Monitoring Kelembaban Gabah Padi Berbasis Arduino," J. Tek. dan Sist. Komput., vol. 1, no. 1, pp. $1-7,2020$.

[10] A. Anantama, A. Apriyantina, S. Samsugi, and F. Rossi, "Alat Pantau Jumlah Pemakaian Daya Listrik Pada Alat Elektronik Berbasis Arduino UNO," $J$. Teknol. dan Sist. Tertanam, vol. 1, no. 1, pp. 29-34, 2020.

[11] A. Pangestu, A. Z. Iftikhor, Damayanti, and M. Bakri, "Sistem Rumah Cerdas Berbasis IoT Dengan Mikrokontroler NodeMCU dan Aplikasi Telegram," J. Tek. dan Sist. Komput., vol. 1, no. 1, pp. 8-14, 2020. 